\title{
A Fast Autonomous Scaled Ship for Experimental Seakeeping Control Studies
}

\author{
S. Esteban, J. Recas, J.M. Giron-Sierra, \\ J.M. De la Cruz, and J.M. Riola \\ Dep. ACYA, Fac. CC. Fisicas, Universidad Complutense de Madrid \\ Ciudad Universitaria \\ 28040 Madrid, Spain. \\ gironsi@dacya.ucm.es \\ (1) Canal de Experiencias Hidrodinamicas. CEHIPAR \\ El Pardo. Madrid, Spain
}

\begin{abstract}
A second part of our research on the seakeeping control in fast ferries, is devoted to general heading and sea state conditions. Although scaled ships are basis for experimental studies, it is not possible to keep using them in towing tanks. The main reason is that high speeds require large space for experiments, so towing tanks are not large enough. This has been noticed after the first part of our research, with head seas, in a $150 \mathrm{~m} \times 30 \mathrm{~m}$ towing tank with wavemaker. Consequently, we are preparing for open air experiments. A new fast autonomous scaled ship has been developed. She is self-propelled, and is self-governed by an embedded PC on-board. The ship carries sensors for heading, speed and seakeeping control. Several scaled moving appendages have been added: two transom flaps, two lateral fins, and a T-foil. The ship uses two scaled waterjets, which also control the heading: the ship has no rudder. A distributed monitoring and control system has been designed and implemented for on-board operation. All equipment has to be very light, since the real fast ferry that we reproduce at $1 / 40$ scale is aluminium made. A digital radio link has been provided for distant off-shore monitoring. The paper describes the autonomous ship, the on-board monitoring and control system, and shows several experimental results with quiet waters and with several types of waves.
\end{abstract}

\section{INTRODUCTION}

Several years ago our research team began to study seakeeping problems in order to develop ride control systems for fast ships. To simplify the issue during initial steps, only head seas were considered, [1] and [2]. A 1/25 scaled ship was built for seakeeping experiments in a towing tank facility. Scaled actuators, such a T-foil near the bow, lateral fins and transom flaps were added to the scaled ship. Figure 1 shows a schematic view of the ship and the actuators. The actuator wings move to counteract each encountered wave.

The real ship is an aluminum made deep- $V$ monobull, $110 \mathrm{~m}$. long, 1200 passengers, and 40 knots as the usual speed.

The towing tnak facility is "El Canal de Experiencias Hidrodinamicas de El Pardo" (CEHIPAR), near Madrid. Lift and drag characterisitics of the actuators were measured in the $300 \mathrm{~m}$. long quiet water channel. Ship motions in response to several types of ocean wave spectra were measured in a $150 \mathrm{~m} \times 30 \mathrm{~m}$. towing tank, $5 \mathrm{~m}$. deep, with wavemaker and a computerized planar motion carriage (towing the sclaed ship).

Afer successful results with modeling and control of the ship, with head seas, a second step of the research recently began.

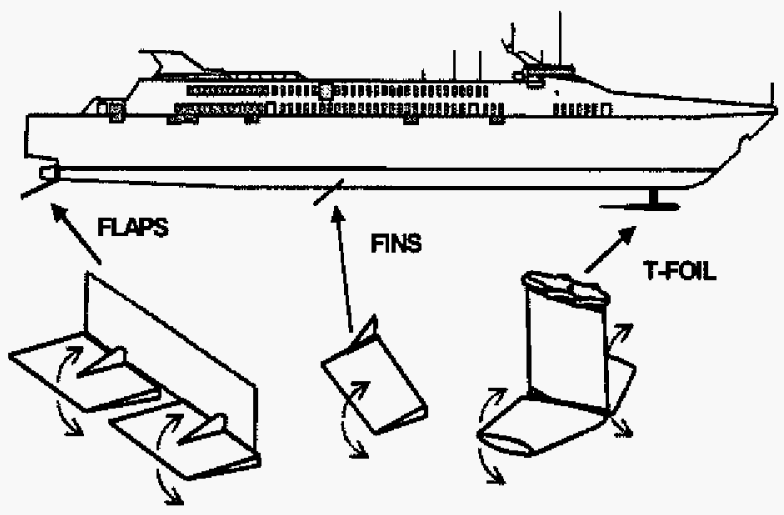

Fig. 1. Schematic view of the ship and the actuators: the T-foil near the bow, lateral fins, and two transom flaps.

In the new research step, a six degrees of freedom problem is considered, with any heading respect to waves. The seakeeping control must mainly attenuate pitch and roll motions. But the six motions of the ship are coupled, so the actuator effects are not simple. The research requires experiments with several beadings at high speed. However there are important difficulties to continue with the $1 / 25$ scaled ship and the towing carriage in the $150 \mathrm{~m} \times 30 \mathrm{~m}$. basin. A main problem is that $30 \mathrm{~m}$. is not wide enough for certain heading angles. In consequence, a new, smaller, 1/40 scaled ship has been developed, with autonomous features. This ship will not be towed. There are no wires connecting the ship with external apparatus. The ship is able to work on open air scenarios, such lakes or large ponds.

This paper focuses in the development and characteristics of the new autonomous scaled ship. In particular, the paper describes in more detail the ship control system architecture and functionality, and aspects of the on-board sensorial system.

The ship is now operational. Some experimental series have been done, and some initial results have been obtained with excellent perspectives.

The order in the paper is as follows. First, a conceptual view of the ship: the main blocks, some basic constructive requierements, and the on-board electronic system architecture. Second, the paper describes the autonomous control of the ship. Then, a section is devoted to the sensorial system. The next section briefly describes a radio-linked external monitoring system. And the last section presents some experimental results. Finally, some conclusions are drawn. 


\section{CONCEPTUAL DESIGN OF THE SHIP}

The purpose of the $1 / 40$ scaled ship is to navigate using its own proputsion, using the on-board control system to keep a specified heading and speed, and uisng their scaled actuators to alleviate the ship motions caused by encountered waves. The on-board control system is also in cherge of controlling the actuator motions. Relevant data about the ship dynamic behavior must be measured and recorded by the on-board electronic system.

In general, seakeeping experiments to be done with the ship in the CEHIPAR basin have the following protocol:

- A sea condition is specified. For instance a SSN5 (sea state 5) with JONSWAP spectrum.

- A ship speed and trajectory is specified. This is made from the coast, using a digital radio link with the ship.

- Waves are generated.

- A radio signal is sent to the ship, telling her to start moving.

- The ship follows the trajectory specified. Ship motion data are measured and recorded. Some of the data are also sent, via radio, to the coast for real-time monitoring.

- At the end of the specified trajectory the ship stops. All recorded data can be recovered from the coast.

During an experiment it is always possible to take control from the coast, overriding the on-board control. Trajectories are specified by way points. Data tecorded on-board, are stored in a flash card (the same used in digital cameras) that can be recovered from the ship.

The data obtained during experiments are the accelerations of the six motions, the three rotation angles, and the ship's speed.

It is clear that open air experiments do not offer the possibility of specifying the sea state. However, it is always possible to compare the ship behavior with seakeeping control and with no seakeeping control. Moreover, ample spaces are interesting for combined maneuvering and seakeeping studies.

Figure 2 shows a block diagram of the ship. The block devoted to radio communications has two links. One of the links is a digital data channel, for real-time monitoring. The other is a conventional $\mathrm{R} / \mathrm{C}$ channel for the manual control of the ship, overriding the ship own control.

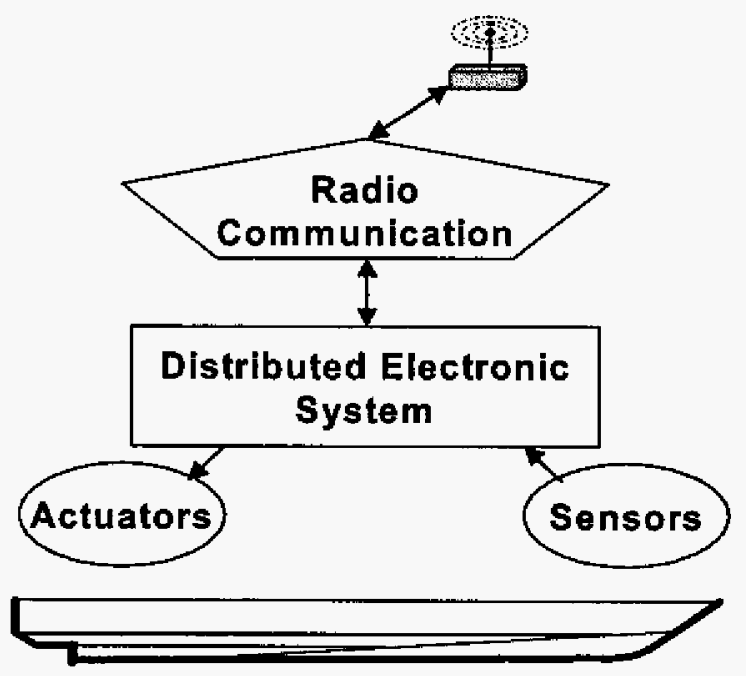

Fig. 2. Block diagram of the ship system.

\section{BASIC CONSTRUCTIVE ASPECTS}

A main challenge for the development of the new ship is that the fast ferry under study is aluminum made. It means that the scaled down weight is $29 \mathrm{Kg}$. Scaled waterjets are included in the scaled ship. The waterjets need sometimes 30 amps., to reach fast speeds. Poweful batteries are needed, and this implies weight. All on-board electronics and actuators must be very light.

The hull itself must be very light. It has been built in fiber and solid foam, with some balsa reinforcements.

Part of the practical research focused on batteries, to determine the best choice. Ni-Cad bigh power batteries have been selected.

The dimensions and location of the actuators have been given by industrial advisors. High-torque rapid $\mathrm{R} / \mathrm{C}$ servos have been selected to move the actuator submerged wings.

Some photogtaphs with constructive details are shown in the next figures.

The inertias of the scaled ship have been adjusted, using ballast, to correspond to the real ship. Figure 3 shows a photograph of the ship during the inertia adjusting process.

Figure 4 shows the ship hanging from ellastic links in our laboratory. Motions are manually caused, to ceck the on-board sensorial and control system (actuators must move with the correct sign).

Figure 5 shows in more detail the T-foil under the bow, while figure 6 shows a photograph of one of the lateral fins.

Finally, figure 7 shows a view of the stern with the waterjets and the flaps below the waterjets. The orientation of the waterjets is controlled by R/C servos. The ship has no rudder. The heading of the ship is determined by moving (twisting) the waterjets. It is also possible to get reverse motion, by using a extensible appendages which tevert the waterjet outputs. This is a good feature for our experiments in the basin, since the ship can stop in short distances.

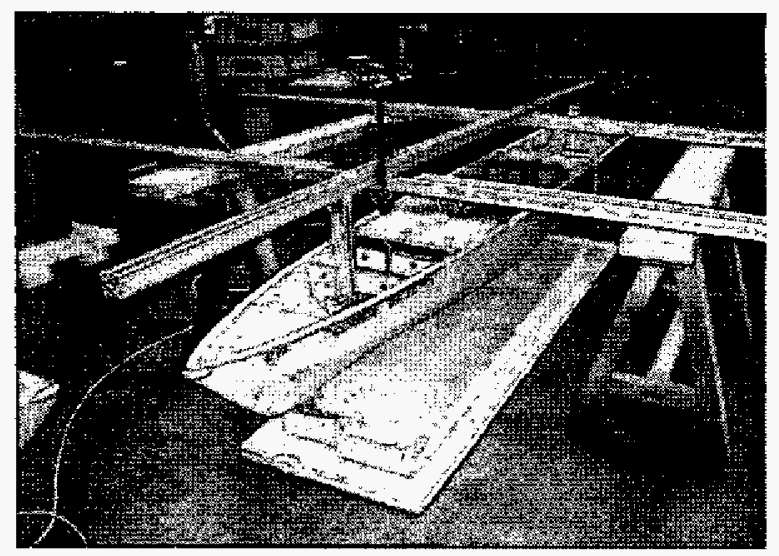

Fig. 3. Photograph of the ship while inertias adjusting.

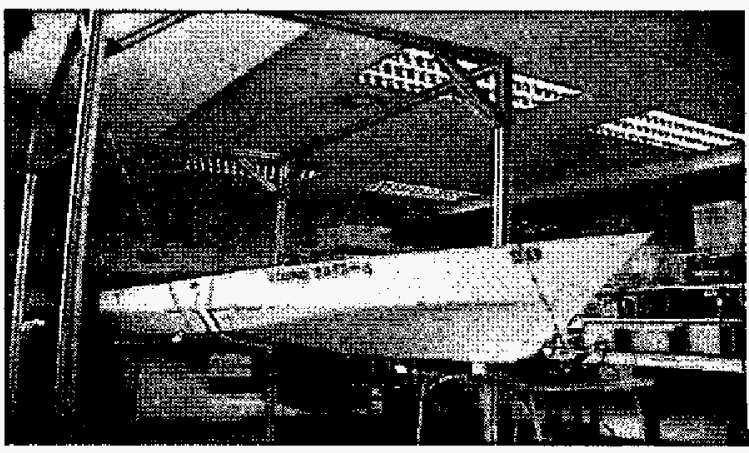

Fig. 4. The ship hanging from elastic links in our laboratory. 


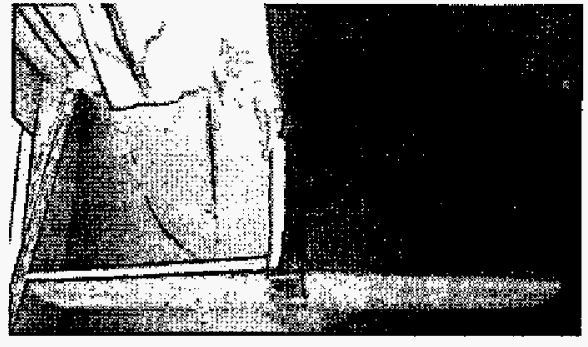

Fig. 5, Detail of the T-foil.

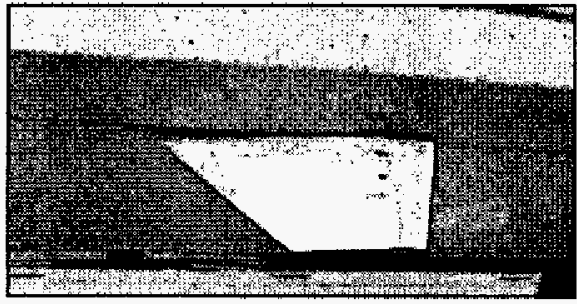

Fig. 6. One of the lateral fins.

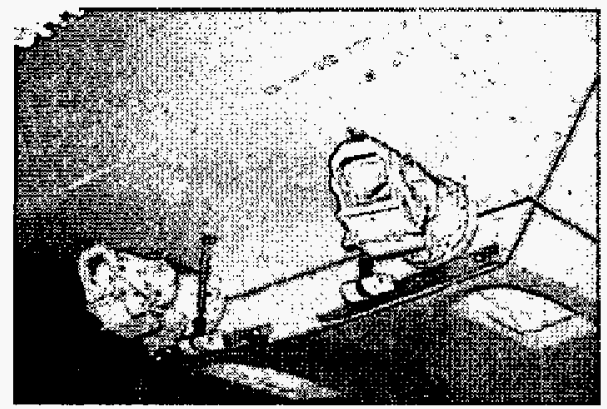

Fig. 7. Waterjets and flaps.

\section{ON-BOARD DISTRIBUTED ELECTRONIC SYSTEM}

An on-board distributed monitoring and control system was developed and implemented in the scaled ship. The system architecture is based on the use of a CANbus. Six nodes have been provided. Each node is centered around a $\mathrm{CAN}$-enabled microcontroller, that can be re-programmed on the field. Figure 8 shows a diagram of the system distributed architecture. Ellipses corrspond to system nodes.

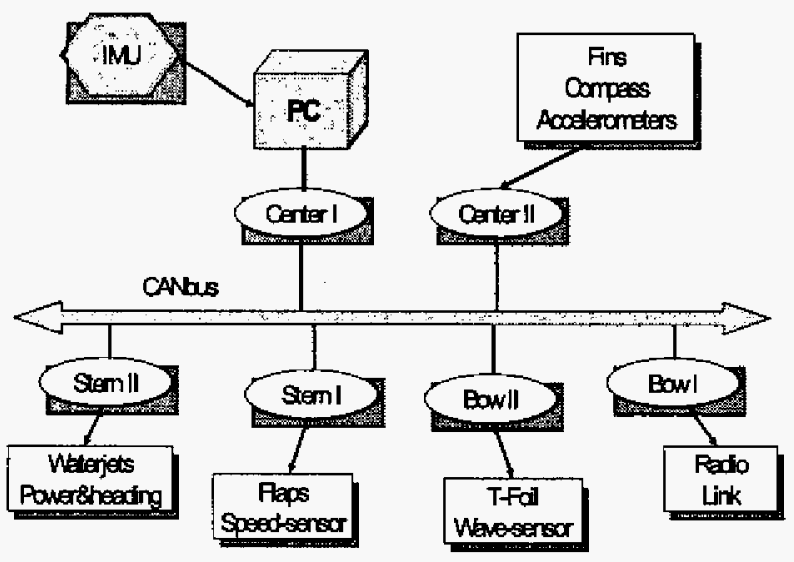

Fig. 8. System distributed architecture.
The several tasks of the distributed system have been assigned to the nodes, so, for instance, one of the nodes is in charge of the lateral fins, and the compass and acceletometers measurements, another node is in charge of the radio-link, etc.

The heart of the system is a low-power, small form, embedded PC. This PC is connected with a CANbus node via serial port. Another serial port of the $\mathrm{PC}$ is used to exchange information with a miniaturized low weight, small, imertial unit.

One of the missions of the microcontroliers at the CANbus nodes is to simulate the dynamic charcaterisitics of the actuators in the real ship, which use hydraulic cylinders.

A messaging system has been designed to allow for monitoring and control coordination in the electronic system, and for data exchange with the coast.

\section{AUTONOMOUS CONTROL}

The first necessary thing to be ensured, before starting with seakeeping experiments, is a good speed and course control.

Figure 9 shows the ship's speed control loop. Velocity is measured with a paddle-wheel. The electrical power applied to the waterjets is adjusted by a PI controller. Some feed-forward action is added to have the electric motors running when reference is reached and maintained.

Figure 10 shows the course control loop. A compensated digital compass is used. The orientation of the waterjet outputs is cadjusted by a PD controller.

Both PI and PD controllers have been tuned in simulation and then the tuning has been improved in experimental studies.

Figure 11 shows in general blocks the seakeeping control loops. The real-time information needed by the fins, flaps and T-foil controllers is made using filters and gain-phase compensation circuits. The main sensors for seakeeping control ate accelerometers.

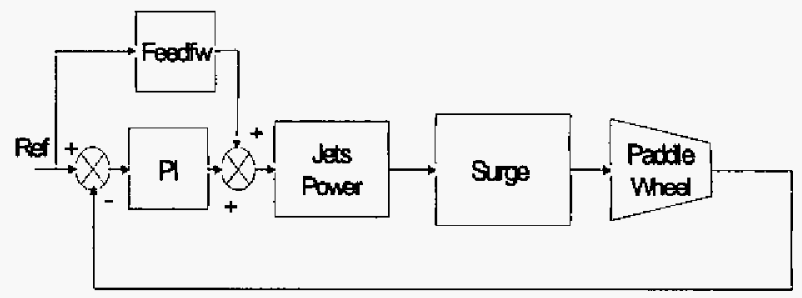

Fig. 9. Speed control loop.

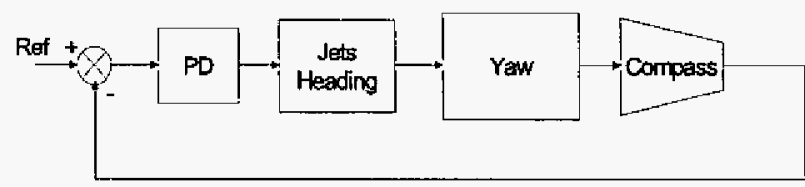

Fig. 10. Course control loop.

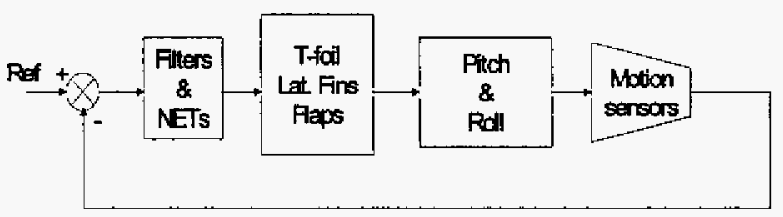

Fig. 11. Seakeeping control loops. 


\section{SENSORS}

Two sets of sensors were included into the on-board control of the autonomous ship. One of the sets is used for control purposes The other set is for scientific purposes, to study the quality of the ship control solutions. Both sets are independent, also in their functional characteristics. The CANbus based architecture of the on-board system allows for both systems to work in parallel.

A criterion for the selection of sensors to be applied in control functions, is that they could be used in real scale ships, being not so expensive as an inertial unit. Due to the metallic roof of the CEHIPAR basin, we do not use GPS in the scaled ship. Of course, GPS can be used, with clear advantages, in real scale ships for some of the control functions.

The sensors we selected for seakeeping ship motion control are three 2-axis accelerometers. The location of the accelerometers allows for the measurement of the six ship accelerations during the ship motions in response to waves. As mentioned before, for the speed and course control loops, velocity is measured with a paddlewheel, and heading angle with a digital compass.

The set of sensors for scjentific purposes is embodied in the inertial unit, which includes the following:

- 3-axis accelerometers with a $\pm 20 \mathrm{~ms}-2$ range, a $30 \mathrm{~Hz}$ bandwidth and a noise of $0.01 \mathrm{mms}$.

- 3-axis gyroscope with a $\pm 900^{\circ} \mathrm{s}-1$ range, a $50 \mathrm{~Hz}$ bandwidth and a noise of $0.7 \mathrm{mms}$.

- 3-axis magnetic flux sensor with a $\pm 750 \mathrm{mGauss}$ range, a $10 \mathrm{~Hz}$ bandwidth and a noise of $4.5 \mathrm{mms}$.

Some of the sensors are good at low frequencies, other at relatively high frequencies. This has been taken into account to deduce roll, pitch and heave from the inertial unit signals. Figure 12 shows the filtering and information fusion that has been devised after many experiments.

Roll and pitch low frequency components can be obtained from low-pass filtering (LPF) of accelerometers. By integtation and high-pass filtering (HPF) of the gyroscope outputs, the high frequency components of pitch, roll and yaw can be obtained. Yaw low frequencies can be derived from magnetic flux sensors, being corrected taking into account the instantaneous roll and pitch of the sensor itself.

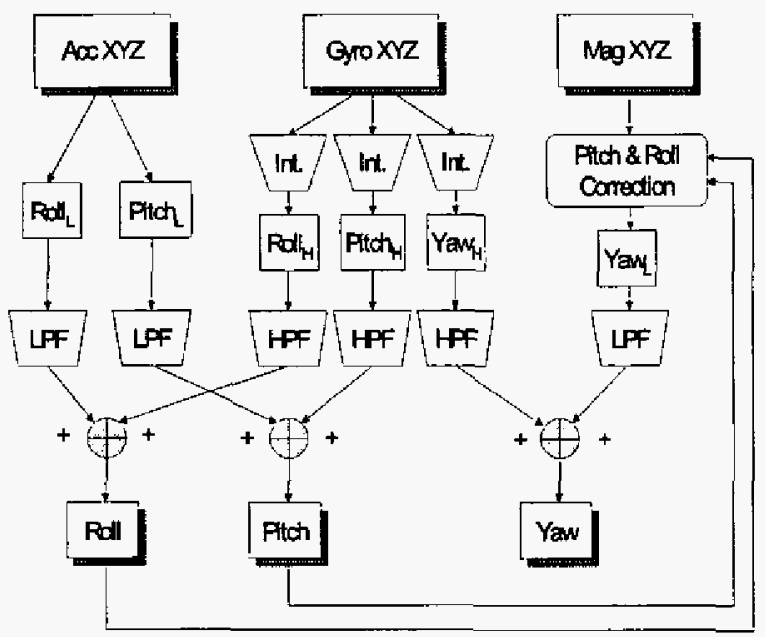

The fusion of low and high frequencies is easy, since HPF and LPF filters are complementary (their transfer functions add to one). They are simple discrete filters, with the following transfer functions:

$$
\begin{gathered}
\operatorname{LPF}(z)=\frac{0.05 z}{z-0.95} \\
H P F(z)=1-\operatorname{LPF}(z)=\frac{z-1}{z-0.95}
\end{gathered}
$$

Obviously it is advantageous to combine both sensor sets, especially for self-localization purposes. For instance, figure 13 shows an experiment with the autonomous ship in the CEHIPAR basin. The ship has to follow a rectangular trajectory. The figure shows a view from the top. The dashed curve is the ship position evolution as measured using the gyroscopes. The dotted curve shows the position measurements using the magnetic sensors. A fusion of both sources of information has been developed, with good agreement with real trajectory of the ship, shown in the solid curve.

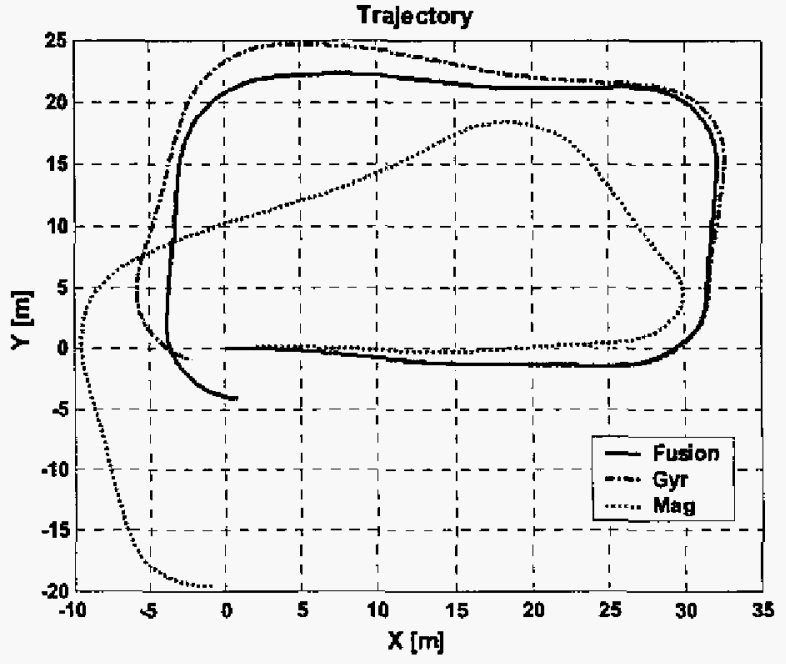

Fig. 13. Fusion of sensors in a rectangular ship trajectory

\section{EXTERNAL SUPPORT SYSTEM}

An experimental support system (ESS) has been also developed. The ESS is linked via radio with the scaled ship. The typical scenario during the experiments in the CEHIPAR towing tank is having the ESS at the border of the basin. In open air scenarios, the ESS may be on the coast, or perhaps on-board a boat. The ESS system is used to tell to the ship the specifications of each experiment (ship's speed and trajectory). During experiments, the ESS receives motion data from the ship. The data are displayed with animated graphics. Figure 14 shows one of the ESS screens during a experiment.

The ESS is also used, with other data plotting screens, for data representation and analysis after experiments. For instance, the ship motion data recorded along one experiment, can be reproduced with animated graphics using the screen with the three views of the ship.

Fig. 12. Inertial unit sensors treatement. 


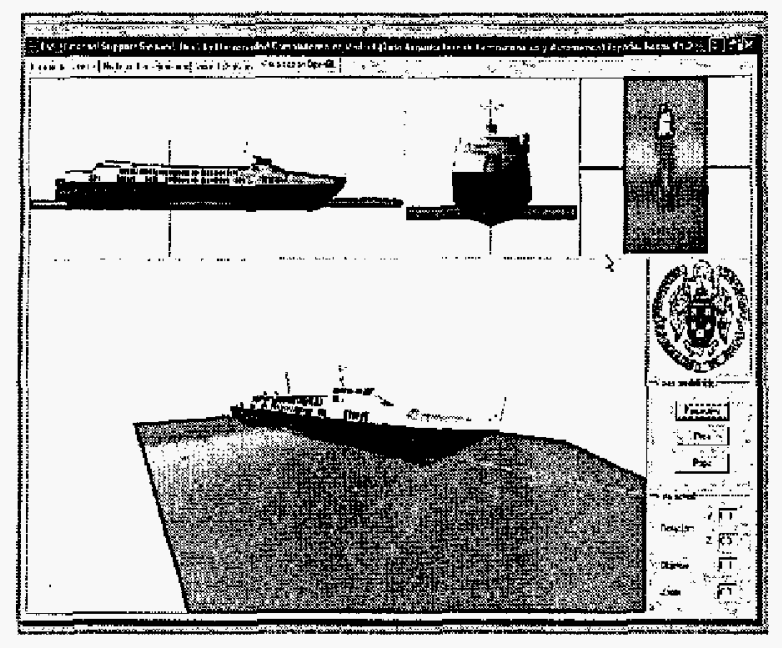

Fig. 14. ESS main screen with animated graphics.

\section{EXPERIMENTAL RESULTS}

After some months of experimental work with the ship, there are some interesting results to be commented. The first problems to be solved were course and speed control. Once these problems were solved, seakeeping control was introduced.

Figure 15 shows the experimental results about course control. Since beading control is done by the orientation of the waterjet outputs, it is important to consider the time constant of the waterjet orientation. A basic model of the yaw dynamics is an integrator. In consequence, a digital PD controller has been designed, with satisfactory experimental results. The results shown in figure 15 have been obtained at high speed ( $3 \mathrm{~m} / \mathrm{s}$, corresponding to 40 knots). The ship starts from $15^{\circ}$ yaw, and corrects her heading to reach and maintain $0^{\circ}$ yaw.

Figure 16 shows experimental results with the speed control. The ship starts a rum and then, after 30 sec., stops. Speed measurements are normalized between 0 and 1 , where 1 is maximum power $(6 \mathrm{~m} / \mathrm{s})$. The figure shows the case having as target a ship's speed of $0.5(3 \mathrm{~m} / \mathrm{s})$.

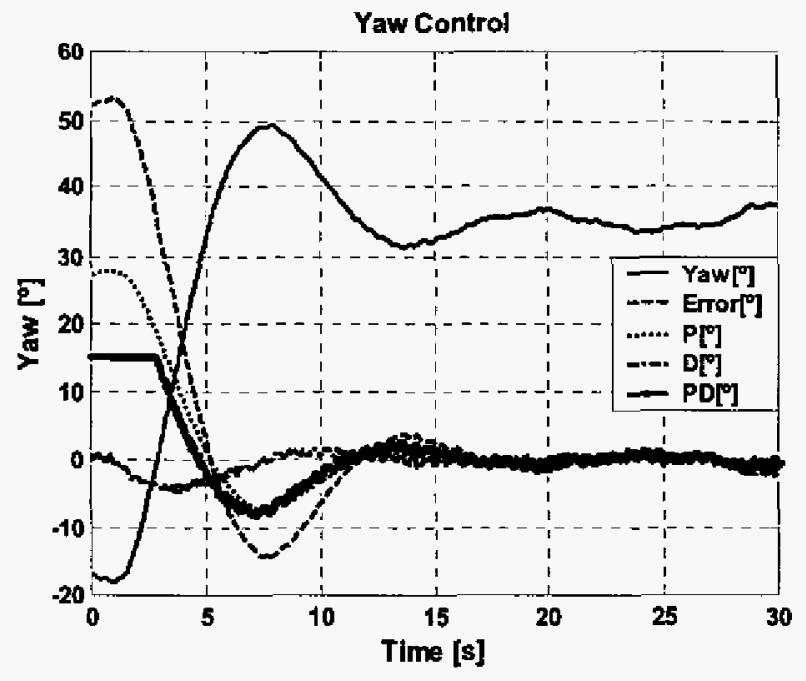

Fig. 15. Course PD control experiment.

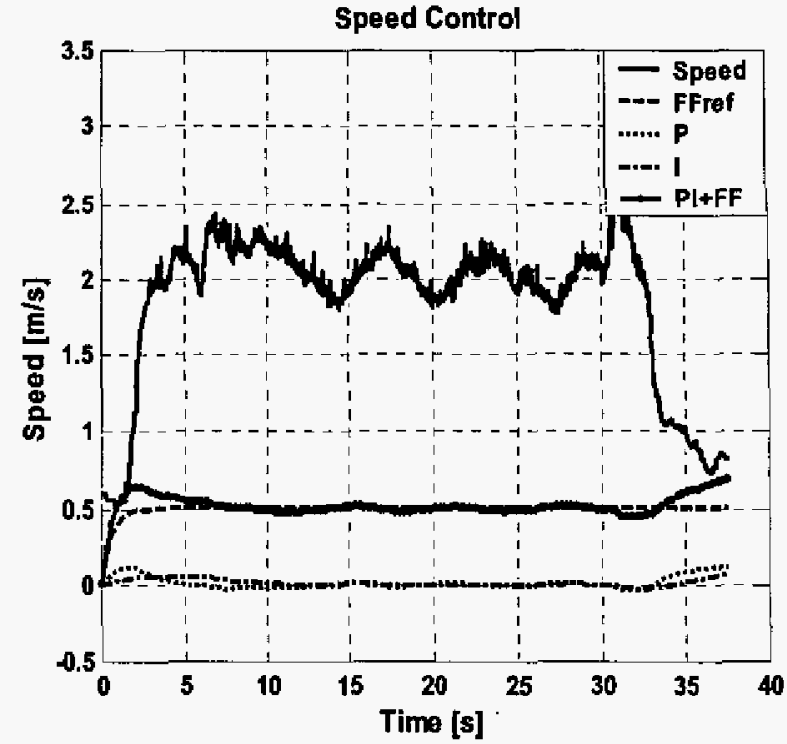

Fig. 16. Speed PI and feedforward control experiment.

Seakeeping control is the most difficult target. The main purpose of this control is to reduce as much as possible the pitch and roll accelerations. Pass-band filters must be applied to extract from the accelerometers the frequencies of interest for control. The DC components of signals must be eliminated. On the other hand, the noise of accelerometers, which are high frequencies, must be also eliminated. The filters must have a flat phase in the pass-band, to favour a simpler control design.

Figure 17 shows the good results obtained by the T-foil motions, the continuous curve with large excursions, in ordet to minimise the vertical accelerations at the bow (mainly pitch), the dashed curve. Notice how the T-foil opposes to the bow vertical accelerations.

Figure 18 shows the experimental results about the alleviation of roll accelerations using the lateral fins. The continuous curve with large excursions shows the fin motions. The dashed curve shows the roll accelerations. The SEAcc-CGAcc signal is obtained subtracting the signals from the accelerometer at the centre of the slip, and from the accelerometer at the side. Although this is a noisy signal, the filters applied for the control are good enough to obtain a clean motion of the fins.

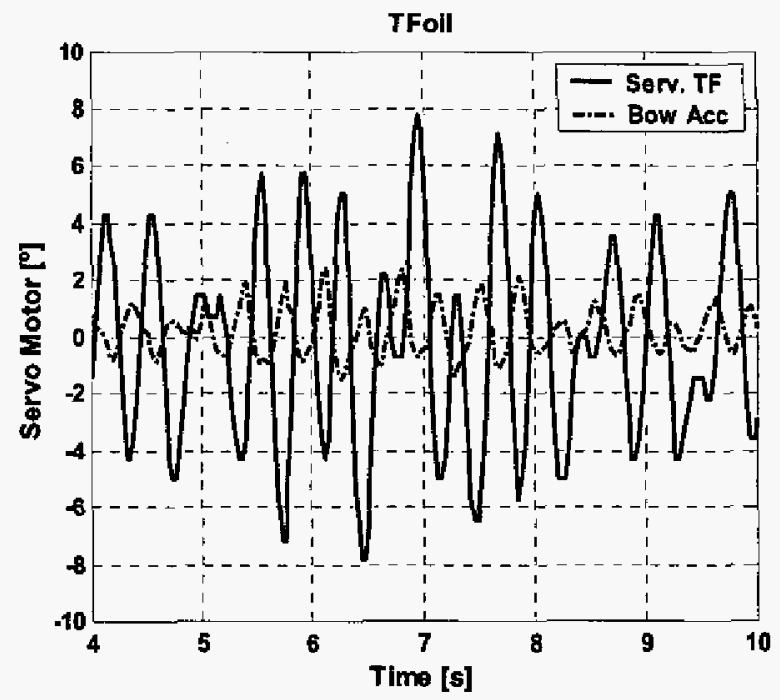

Fig. 17. Smoothing pitch motion with the T-foil. 


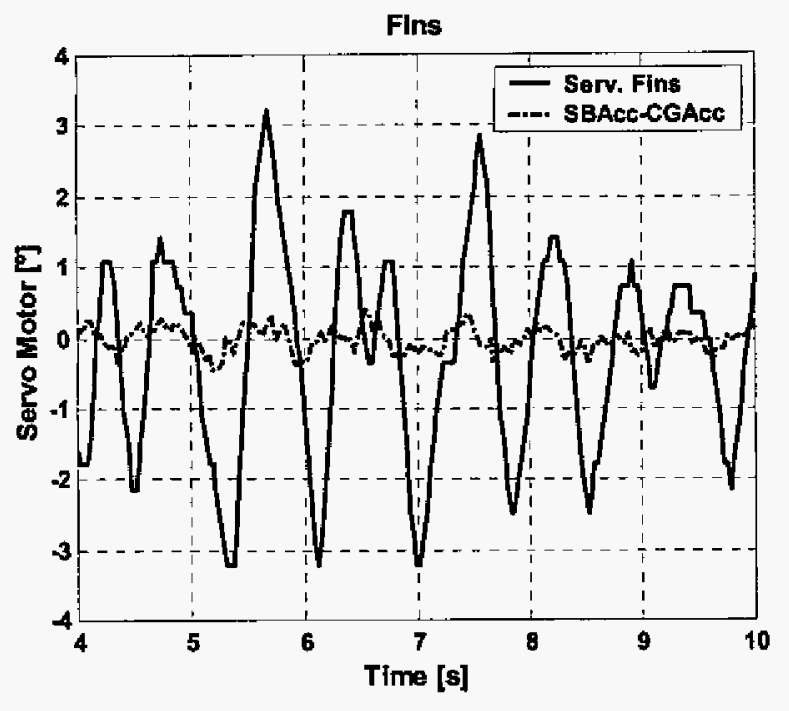

Fig. 18. Smoothing roll motion with the fins.

To highlight the real interest of a new autonomous ship, let us show an interesting experimental result just obtained. Figure 19 shows the speed response of the ship to a shut off of the waterjets. After the peak near $6 \mathrm{sec}$. a conventional decreasing exponential curve was expected, corresponding to speed relaxing. However, around 9 sec. there is a brisk downwards change. It seems that this rapid change corresponds to the ship transitioning from surface effect navigation to conventional drag. Actually, the design of the hull promotes this effect. This interesting phenomenon, which is most important, in the reverse sense, to reach high speeds, can be observed in the autonomous ship, and not in the towed one.

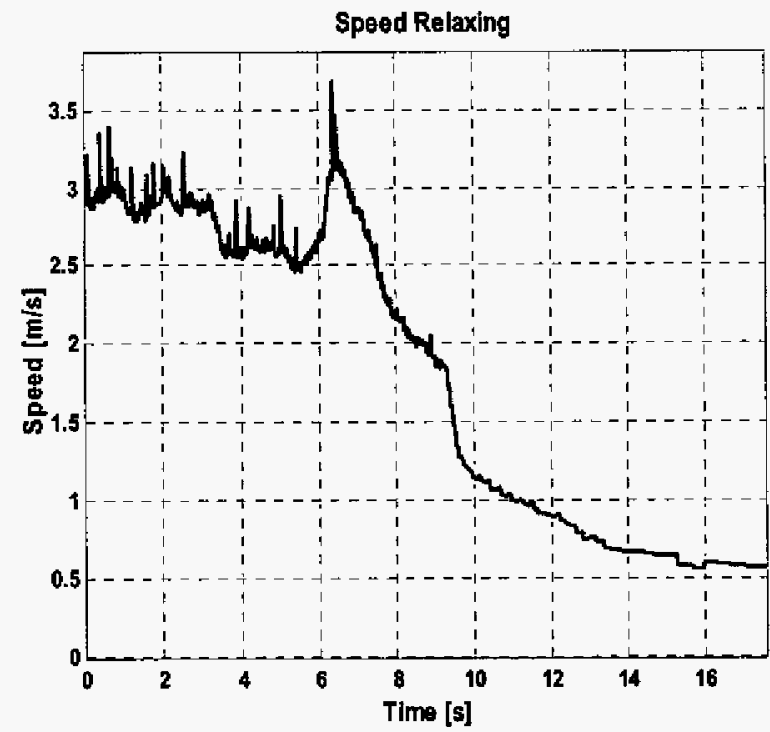

Fig. 19. Surface effect at $2 \mathrm{~m} / \mathrm{s}$

\section{CONCLUSION}

A fast autonomous scaled ship has been developed for experimental seakeeping studies, in towing tanks or in open air scenarios.

The paper described the conceptual architecture of the on-board electronic system. This system consists in several microcontrollers and an embedded $\mathrm{PC}$, around a CANbus. The system has been conceived to be usable in real scale ships, since the CANbus can reach kilometers. We made some studies confirming that real scale ships would require less messaging and sampling speed of the measurement and control system, compensating for the decrease of the CANbus bandwith. Actually, the 1/40 scale autonomous ships poses more stringent conditions for the digital processing and communication, than for real scale.

Ship speed, course and seakeeping autonomous control has been achieved, with experimental coonfirmation.

The scaled ship is now ready for control experimental studies, trying several control strategies in different sea, heading and speed conditions [3].

An external support system (ESS) has been also developed, with a digital radio-link with the scaled ship. This is used for experimental and data analysis tasks. One of its functions is real-time ship behavior moonitoring. Indeed, it can be connected to Internet for distance experiments.

The research in the near future will exploit the ship for systematic experiments in CEHIPAR, and for open air experiments with some combined maneuvering and seakeeping tests.

\section{Acknowledgments}

The authors would like to thank the Spanish MCYT, "Ministerio de Ciencia y Tecnologia", for their support (project DPI2000-0386-C03-02), the CEHIPAR staff for their cooperation, and IZAR for its recommendations.

\section{REFERENCES}

[1] J.M. Giron-Sierra, S. Esteban, B. De Andres, J.M. Diaz and J.M. Riola, "Experimental study of controlled flaps and T-foil for comfort improvement of a fast ferry," in Proceedings IFAC Intl. Conf. Control Applications in Marine Systems CAMS2001, Glasgow, 2001.

[2] J.M. De la Cruz, J. Aranda, J.M. Giron-Sierra, F. Velasco, S. Esteban, J.M. Diaz, and B. De Andres,"Improving the comfort of a fast ferry with the control of flaps and T-foil," IEEE Control Systems Magazine, vol. 24, 1. 2, pp. 47-60, April 2004.

[3] T.J. Fossen, Marine Control Systems, Marine Cybemetics, AS, 2002. 